\title{
Control of PTH secretion by the TRPC1 ion channel
}

\author{
Marta Onopiuk, ${ }^{1}$ Bonnie Eby, ${ }^{2}$ Vasyl Nesin, ${ }^{1}$ Peter Ngo, ${ }^{1}$ Megan Lerner, ${ }^{3}$ Caroline M. Gorvin, ${ }^{4}$ \\ Victoria J. Stokes, ${ }^{4}$ Rajesh V. Thakker, ${ }^{4}$ Maria Luisa Brandi, ${ }^{5}$ Wenhan Chang, ${ }^{6}$ \\ Mary Beth Humphrey, ${ }^{7,8}$ Leonidas Tsiokas, ${ }^{1}$ and Kai Lau ${ }^{2,8}$ \\ 'Department of Cell Biology and 2Department of Medicine, Division of Nephrology, University of Oklahoma Health \\ Sciences Center, Oklahoma City, Oklahoma, USA. ${ }^{3}$ Department of Surgery, Oklahoma City, Oklahoma, USA. ${ }^{4}$ Academic \\ Endocrine Unit, Radcliffe Department of Medicine, University of Oxford, Oxford, United Kingdom. ${ }^{5}$ Department of \\ Biomedicals Sperimentals and Clinicals Sciences, Università degli Studi di Firenze and Fondazione FIRMO, Florence, Italy. \\ ${ }^{6}$ Endocrinology and Metabolism, Department of Medicine, UCSF, San Francisco, California, USA. ${ }^{7}$ Department of Medicine, \\ Division of Rheumatology, Immunology, and Allergy, University of Oklahoma Health Sciences Center, Oklahoma City, \\ Oklahoma, USA. ${ }^{8}$ Department of Veterans Affairs, Oklahoma City, Oklahoma, USA.
}

Familial hypocalciuric hypercalcemia $(\mathrm{FHH})$ is a genetic condition associated with hypocalciuria, hypercalcemia, and, in some cases, inappropriately high levels of circulating parathyroid hormone (PTH). FHH is associated with inactivating mutations in the gene encoding the $\mathrm{Ca}^{2+}$-sensing receptor (CaSR), a GPCR, and GNA11 encoding G protein subunit $\alpha 11$ (G $\alpha 11)$, implicating defective GPCR signaling as the root pathophysiology for FHH. However, the downstream mechanism by which CaSR activation inhibits PTH production/secretion is incompletely understood. Here, we show that mice lacking the transient receptor potential canonical channel 1 (TRPC1) develop chronic hypercalcemia, hypocalciuria, and elevated PTH levels, mimicking human FHH. Ex vivo and in vitro studies revealed that TRPC1 serves a necessary and sufficient mediator to suppress PTH secretion from parathyroid glands (PTCs) downstream of CaSR in response to high extracellular $\mathrm{Ca}^{2+}$ concentration. Ga11 physically interacted with both the $\mathrm{N}$ - and C-termini of TRPC1 and enhanced CaSR-induced TRPC1 activity in transfected cells. These data identify TRPC1-mediated $\mathrm{Ca}^{2+}$ signaling as an essential component of the cellular apparatus controlling PTH secretion in the PTC downstream of CaSR.

Authorship note: $\mathrm{MO}$ and $\mathrm{BE}$ contributed equally to this work.

Conflict of interest: The authors have declared that no conflict of interest exists.

Copyright: () 2020, Onopiuk et al. This is an open access article published under the terms of the Creative Commons Attribution 4.0 International License

Submitted: August 8, 2019 Accepted: March 16, 2020 Published: April 23, 2020.

Reference information: /CI Insight. 2020;5(8):e132496.

https://doi.org/10.1172/jci. insight.132496.

\section{Introduction}

Parathyroid hormone (PTH) is a critical hormone for $\mathrm{Ca}^{2+}$ homeostasis. In normal conditions, levels of PTH are tightly controlled by serum $\mathrm{Ca}^{2+}$ via a negative feedback mechanism in which high serum $\mathrm{Ca}^{2+}$ levels suppress the production and/or secretion of PTH from the parathyroid gland (PTG). This feedback mechanism prevents the development of hypercalcemia or hypocalcemia. In primary hyperparathyroidism often resulting from PTG adenomas, abnormally high levels of PTH result in hypercalcemia, whereas in secondary hyperparathyroidism, frequently seen in renal failure, elevated PTH levels are actually associated with hypocalcemia. Patients with naturally occurring mutations in the gene encoding the $\mathrm{Ca}^{2+}$-sensing receptor $(C a S R)(1,2)$, GNA11 encoding G protein subunit $\alpha 11$ (Ga11) (3), or AP2S1 encoding the clathrin-associated adaptor protein-2 $\sigma$ subunit $2(\mathrm{AP} 2 \sigma 2)(4)$ develop familial hypocalciuric hypercalcemia $(\mathrm{FHH})$, characterized by hypercalcemia and hypocalciuria and, in some cases, by inappropriately elevated levels (5). Proteins encoded by the FHH-associated genes function in a linear signaling pathway within the PTG to suppress production and secretion of PTH in response to hypercalcemia. However, an outstanding question has been how hypercalcemia causes the suppression of PTH production and secretion. It has been suggested that a critical step involves a transient rise in intracellular $\mathrm{Ca}^{2+}$ concentration in response to high serum $\mathrm{Ca}^{2+}$ levels $(6,7)$. In contrast to most endocrine systems, where an increase in intracellular $\mathrm{Ca}^{2+} \mathrm{Con}_{-}$ centration triggers exocytosis and hormonal release, the PTG is unique in that an increase in intracellular $\mathrm{Ca}^{2+}$ concentration instead suppresses PTH release (7) The molecular identity of the ion channels mediating this transient increase in intracellular $\mathrm{Ca}^{2+}$ concentration driving the suppression of PTH release has been unknown. Therefore, identification of these channels and the mechanisms underlying CaSR-induced 
$\mathrm{Ca}^{2+}$ signaling suppression of PTH secretion are of paramount importance in understanding and treating pathological conditions resulting from abnormal $\mathrm{PTH}$ levels.

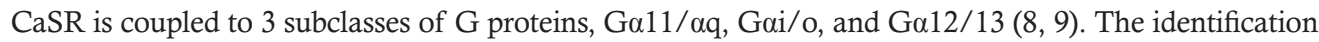
of GNA11 as an FHH-associated gene and further functional and genetic studies on Ga11 indicate that the coupling of CaSR to Ga11 may be directly linked to the suppression of PTH production and/or secretion. Activation of Ga11/ $\alpha$ q-coupled CaSR leads to the generation of inositol trisphosphate $\left(\mathrm{IP}_{3}\right)$, which triggers $\mathrm{Ca}^{2+}$ release from ER and stimulation of $\mathrm{Ca}^{2+}$ influx from the extracellular fluid mediated by store- and/or receptor-operated $\mathrm{Ca}^{2+}$ entry (SOCE and/or ROCE) channels, localized at the plasma membrane. SOCE channels are defined as the channels activated exclusively via the depletion of the intracellular $\mathrm{Ca}^{2+}$ stores following the activation of any pathway that involves the generation of $\mathrm{IP}_{3}$ as a second messenger and involve the $\mathrm{ER} \mathrm{Ca}^{2+}$ sensor, stromal interaction molecule 1 (STIM1), and the pore-forming subunit, Orai1 (10). ROCE channels are activated via intermediaries generated during the activation of cell surface receptors, and nearly all of the 28 known TRP channels can function as ROCE channels, depending on cell and tissue contexts (11, 12). Therefore, theoretically both SOCE and ROCE channels can be activated following the stimulation of the CaSR. Transient receptor potential canonical channel 1 (TRPC1) belongs to the canonical subgroup of TRP channels and has been implicated in both SOCE and ROCE (13). TRPC1 can be activated by CaSR in rabbit mesenteric arteries (14), colonic epithelial $(15,16)$, endothelial (17), and breast cancer cells (18), making it an ideal candidate for mediating the suppression of PTH secretion downstream of CaSR in the PTG.

Using a combination of in vivo, ex vivo, and in vitro approaches, our studies show that TRPC1 functions downstream of CaSR in the suppression of PTH secretion and that Trpc1-null mice show an FHHlike phenotype. However, its mechanism of activation does not involve store depletion but instead involves a protein-protein interaction with $\mathrm{G} \alpha 11$, a protein directly coupled to CaSR and genetically implicated in FHH. Thus, our study identifies TRPC1 as one of the ion channels mediating the mechanism by which high $\mathrm{Ca}^{2+}$ serum levels suppress PTH secretion.

\section{Results}

Trpc1 $^{-1-}$ mice develop FHH. Global Trpc1 $1^{-1-}$ mice have been described previously (19). Homeostatic serum $\mathrm{Ca}^{2+}$ levels were significantly higher in male and female $\operatorname{Tr} c 1^{-1-}$ mice at 7 months of age (Figure 1A). Hypercalcemia was observed at early as 3.5 months and persisted up to 21.5 months in age-matched null littermate males $\left(11.31 \pm 0.28 \mathrm{mg} / \mathrm{dl}\right.$ in $\operatorname{Trp}^{-1 /-}$ vs. $9.92 \pm 0.41 \mathrm{mg} / \mathrm{dl}$ in $\left.\operatorname{Trpc1}^{+/+}, P<0.05\right)$ (Supplemental Figure 1A; supplemental material available online with this article; https://doi.org/10.1172/jci. insight.132496DS1). $\operatorname{Trpc1}^{+/}$male mice exhibited significant hypercalcemia (Supplemental Figure 1B), suggesting that heterozygous deletion of Trpc1 was sufficient to produce a hypercalcemic phenotype. PTH levels were significantly higher in 7-month-old homozygous mutant males and inappropriately high in 7-month-old homozygous mutant females (because they were not suppressed by hypercalcemia as expected in normal physiology) (Figure 1B). Inappropriately high PTH levels were observed in younger and older mice (Supplemental Figure 1C). Hypercalcemia was present in either fasted in $\operatorname{Trpc}^{1^{--}}$mutant male or female mice ( 10 hours prior to blood collection) or animals allowed to feed ad libitum, arguing against increased gut $\mathrm{Ca}^{2+}$ absorption as the mechanism for the hypercalcemia in mice lacking Trpc1 (Supplemental Figure 1D). Despite hypercalcemia, 24-hour urine $\mathrm{Ca}^{2+}$ excretion (Figure 1C), renal Ca ${ }^{2+}$ clearance (Figure 1D), and the urine $\mathrm{Ca}^{2+} /$ creatinine ratio were all reduced in 7-month-old $\mathrm{Trpc1}^{-/-}$males and females (Figure 1E). Reduced urine $\mathrm{Ca}^{2+}$ clearance persisted up to 21.5 months $\left(5.8 \pm 3.4 \mu \mathrm{l} / \mathrm{min}\right.$ in $\operatorname{Trpc1}^{-/-}$males vs. $29.3 \pm 7.9 \mu \mathrm{l} / \mathrm{min}$ in $\operatorname{Trpcl}^{+/+}$males). Serum $\mathrm{Mg}^{2+}$, renal $\mathrm{Mg}^{2+}$ clearance, urine $\mathrm{Mg}^{2+}$ excretion, and the 24-hour urine $\mathrm{Mg}^{2+}$ /creatinine ratio were unaffected by deletion of Trpc1 (Table 1). These data indicate that $\operatorname{Trpc1}^{-/-}$mice are hypocalciuric and that, overall, they show the classic triad of FHH of hypocalciuria, hypercalcemia, and significantly elevated or inappropriately high levels of circulating PTH.

To evaluate if these phenotypes were secondary to renal disease and/or disorders of vitamin $\mathrm{D}$ metabolism, we measured serum levels of $1,25(\mathrm{OH})_{2}$ vitamin $\mathrm{D}$, creatinine, and calcitonin. $1,25(\mathrm{OH})_{2}$ vitamin $\mathrm{D}$ was unchanged in 7-month-old males (Table 1). Similarly, serum creatinine in $\mathrm{Trpc}^{-/-}$mice was similar to that in WT mice at 1 year of age (Table 1). Creatinine clearance in $\operatorname{Trpc1}^{-1-}$ mice was comparable to that in WT mice (Table 1), indicating that renal failure could not have accounted for the hypercalcemia and elevated PTH levels seen in Trpc1 ${ }^{-/-}$mice. Serum phosphorus levels in $\operatorname{Trp} \mathrm{C}^{-1-}$ mice were similar to those in $\operatorname{Trpc}^{+/+}$mice (Table 1). Hematocrits were not different at 8.5 months of age and were lower at 10.5 and 21.5 months of age, showing that hemoconcentration was not responsible for the hypercalcemia (Table 1). 

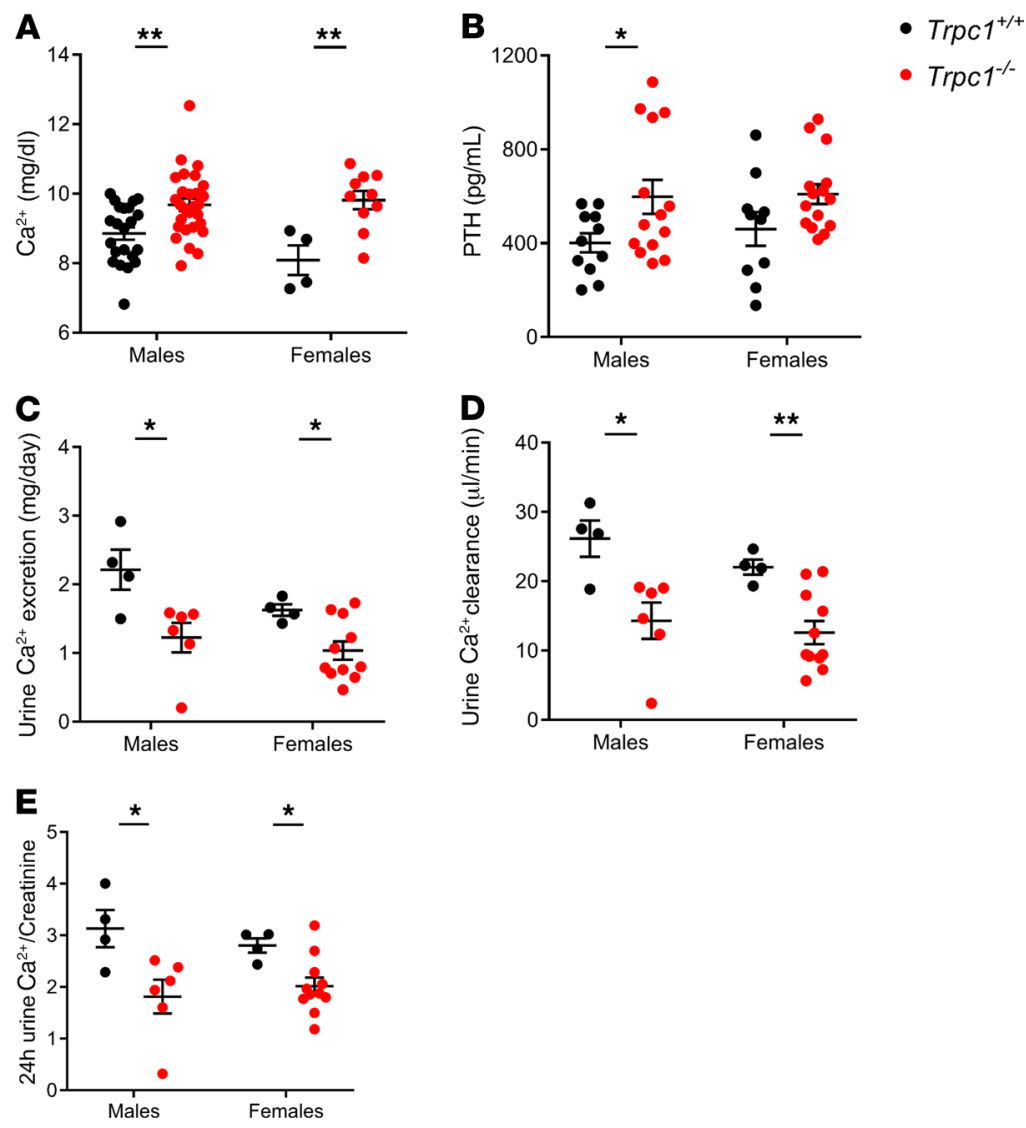

Figure 1. Trpc1--- mice exhibit hypercalcemia, hyperparathyroidism, and hypocalciuria. (A) Serum Ca ${ }^{2+}$ levels (mg/dl) in 7-month-old Trpc1 $1^{+/}$and Trpc1 $1^{-/-}$fasted males and females. ${ }^{* *} P<0.01$, Student's $t$ test. (B) Serum PTH levels (pg/ $\mathrm{ml}$ ) in 7-month-old $\operatorname{Trpc}^{+/+}$and $\operatorname{Trpc} \mathrm{1}^{-/-}$fasted males and females. ${ }^{*} P<0.05$, Student's $t$ test. (C) Urine $\mathrm{Ca}^{2+}$ excretion (mg/day) in 7-month-old $\operatorname{Trpc1^{+/+}}$ and $\operatorname{Trpc1^{-/-}}$ males and females. ${ }^{*} P<0.05$, Student's $t$ test. (D) Ca ${ }^{2+}$ clearance $(\mu \mathrm{l} / \mathrm{min})$ in 7-month-old $\operatorname{Trpc} \mathrm{T}^{1^{++}}$and $\operatorname{Trpc1} 1^{-/-}$males and females. ${ }^{*} P<0.05 ;{ }^{* *} P<0.01$, Student's $t$ test. (E) Twenty-four-hour urine $\mathrm{Ca}^{2+} /$ creatinine ratio in 7-month-old $\operatorname{Trpc1^{+/+}}$ and $\operatorname{Trpc1}{ }^{-/-}$males and females. ${ }^{*} P<0.05$, Student's $t$ test.

Plasma levels of calcitonin, another regulator of serum $\mathrm{Ca}^{2+}$, were unchanged in 7-month-old Trpc1-null males (Table 1), suggesting that deletion of $\operatorname{Trpc1}$ does not affect calcitonin secretion from $\mathrm{C}$ cells of the thyroid gland that could indirectly influence serum $\mathrm{Ca}^{2+}$ and/or PTH secretion.

Despite high PTH levels seen in primary hyperparathyroidism typically being associated with low bone mass and osteoporosis, patients with FHH manifest slightly reduced, normal, or even increased bone mass $(20,21)$. Mildly increased bone mass is also seen in mice lacking the CaSR in the PTG (22). Our previous work has shown that 12-week-old male $\operatorname{Trpc1}^{-1-}$ mice have slightly increased bone mass (23). We extended the analysis to 19-month-old animals and found that $\operatorname{Trpc1}^{-1-}$ mice had $83 \%$ increase in bone volume to tissue volume, $27 \%$ reduction in trabecular spacing, 36\% increase in trabecular number and $181 \%$ increase in connectivity density (Supplemental Figure 2, A-D).

TRPC1 mutations not detected in patients with FHH. The phenotype of the Trpc1 $1^{-1-}$ mice is consistent with that of FHH in humans, and the possibility that mutations in the TRPC1 gene may be a cause of hypercalcemia in some patients with FHH who did not have CASR, GNA11, or AP2S1 mutations was therefore explored. Sanger DNA sequence analysis (14 patients) or whole exome sequencing (5 patients) did not detect any point mutations, deletions, insertions, or unreported SNPs. However, a 16-bp segment corresponding to the 5'UTR in short form of TRPC1 or amino acid residues VGAGG in long form of TRPC1 (Supplemental Figure 3) could not be reliably ascertained due to repetitive elements. A binomial analysis predicted that the use of 19 samples in total would have a greater than $95 \%$ and $98 \%$ likelihood of detecting at least 1 TRPC 1 mutation, assuming a mutation prevalence of $15 \%$ and $20 \%$, respectively (24). Whole exome sequencing did identify a common polymorphism (p.A14T, present in 7490 of 261,160 alleles in the gnomAD v2.1.1 database) in 1 patient with $\mathrm{FHH}$. 
Table 1. Serum and urine analysis of biochemical parameters in $\operatorname{Trpc1}^{+/+}$and $\operatorname{Trpc1}^{-1^{-}}$male mice

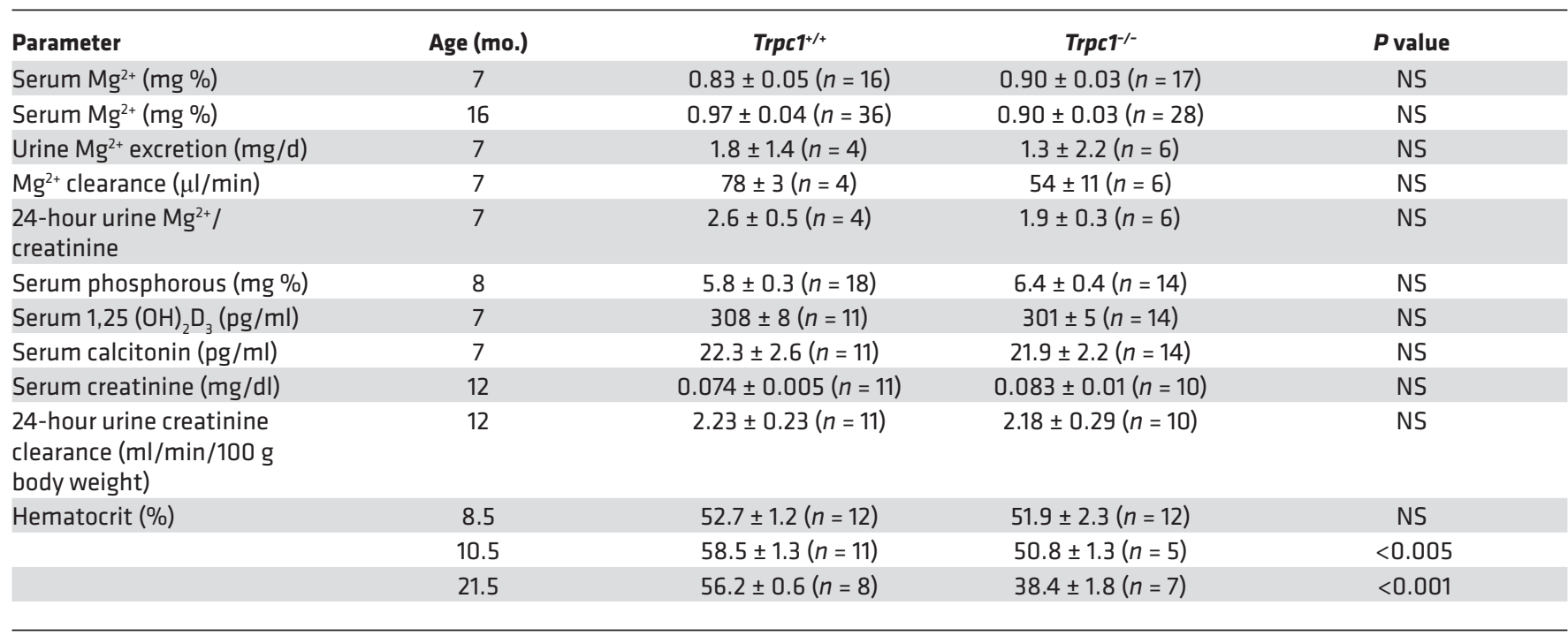

TRPC1 is required for the suppression of PTH secretion in isolated mouse PTGs. TRPC1 was widely expressed in WT but not in mutant PTGs (Figure 2A). To test for a PTG-autonomous effect of TRPC1 on PTH secretion, we determined the secretory capacity of isolated PTGs from groups of both 14-week-old male and female mice, as was done previously for the CaSR (22). Male and female mice had similar PTH secretion maximum ( Rmax) and minimum ( $\mathrm{Rmin}$ ) as well as $\mathrm{Ca}^{2+}$ set points; therefore, we pooled the data to increase the power of the analysis. Absolute Rmax values were approximately 3-fold higher in $\operatorname{Trpc}^{-/-}$PTGs compared with those in $\operatorname{Trpcl}^{+/+}$PTGs (Figure 2B), accompanied by a significant $(P<0.05)$ rightward shift in the $\mathrm{Ca}^{2+}$ set point from $1.04 \pm 0.15 \mathrm{mM}$ in $\operatorname{Trpc1} 1^{+/+}$mice to $1.25 \pm 0.08 \mathrm{mM}$ in $\operatorname{Trpc}^{1^{-/}}$mice (Figure 2C). These ex vivo effects were more severe than the deletion of 1 allele of Casr in the PTGs of 3-month-old mice but less severe than the deletion of 2 Casr alleles $(22,25)$, suggesting that TRPC1 may significantly contribute (by more than $50 \%$ ) to the effects of CaSR in the secretion of PTH from the isolated PTG.

Parathyroid cells depleted of TRPC1 secrete more PTH. Derived from rat PTG, PTH-C1 cells express CaSR, produce and secrete PTH, and are currently the only known cell line available for studying PTH secretion in rodents (26). Using CRISPR/Cas9 gene editing, we introduced a frameshift in the Trpc1 locus in PTH-C1 cells and generated several stable clones. One of these clones, PTH-C1 ${ }^{\text {Trpcl-KO }}$ (Supplemental Figure 4, A and D), was used for functional PTH secretion assays. Deletion of TRPC1 led to a $44 \%$ increase in secreted PTH (from $8.7 \pm 0.8 \mathrm{pg}$ / $\mathrm{ml}$ in WT cells to $12.6 \pm 1.2 \mathrm{pg} / \mathrm{ml}$ in PTH-C1 $1^{\text {Trpl-KO }}$ cells) in the presence of low extracellular $\mathrm{Ca}^{2+}$ concentration $\left(0.5 \mathrm{mM} \mathrm{Ca}^{2+}\right)$, which should promote PTH secretion (Figure $\left.3 \mathrm{~A}\right)$. Similar effects were seen when PTH-C1 cells were treated with Pico145, a specific inhibitor of TRPC1/TRPC4/TRPC4 channels (27) (Supplemental Figure 5A). RT-PCR failed to detect TRPC4 or TRPC5 mRNAs in PTH-C1 cells, indicating that Pico145 increased PTH secretion, most likely by inhibiting endogenous TRPC1 in these cells (Supplemental Figure 5B).

To examine whether endogenous TRPC1 controls PTH secretion rather than gene expression, we generated and characterized stable clones overexpressing mouse PTH using a heterologous promoter (CMV) that should not be affected by TRPC1 levels. Two individual clones highly expressing PTH (PTH-C1 $1^{\text {Pth }-1} \sim 20,000$ fold and PTH-C1 ${ }^{\text {Pth-2 }} \sim 2,000$-fold compared with parental PTH-C1 cells) were subsequently transfected with a TRPC1-specific CRISPR/Cas9 construct, and two individual clones (PTH-C1 ${ }^{\text {Pth }-1 / \text { Trpcl-KO }^{-K}}$ and PTH-C1 ${ }^{\text {Pth-2/Trpcl- }}$ ${ }^{\mathrm{KO}}$ ) with complete deletion of TRPC1 (verified by Sanger sequencing of the recombination site at the Trpc1 locus, Supplemental Figure 4, B and C) were used for functional assays. PTH-C1 ${ }^{\text {Pth-1/Trpcl-KO }}$ cells secrete 50.9 $\pm 2.7 \mathrm{ng} / \mathrm{ml} \mathrm{PTH}$, which was $106 \%$ higher than that of PTH-C1 ${ }^{\text {Pth }-1}$ cells $(24.8 \pm 2.0 \mathrm{ng} / \mathrm{ml}$ ) (Figure 3B). Similarly, PTH-C1 ${ }^{\text {Pth-2/Trpc-KO }}$ cells showed $85 \%$ higher PTH secretion $(4574 \pm 48$ pg/ml) compared with PTH$\mathrm{C1}^{\text {Pth-2 }}$ cells $(2473 \pm 53 \mathrm{pg} / \mathrm{ml}$ ) (Figure $3 \mathrm{C}$ ). Transfecting back WT TRPC1 $\alpha$ suppressed PTH secretion by $31 \%$ in PTH-C1 ${ }^{\text {Pth-2/Trpcl-KO }}$ cells (Figure 3E). However, transfection of TRPC1 $\alpha$ F689A, with a single amino acid mutation in its pore region (Figure 3D) that reduces $\mathrm{Ca}^{2+}$ permeability (28) and CaSR-induced $\mathrm{Ca}^{2+}$ influx (Figure $3 \mathrm{~F}$ ), failed to suppress PTH secretion $(0.7 \%)$ in these cells (Figure $3 \mathrm{E}$ ). In the presence of mutant 


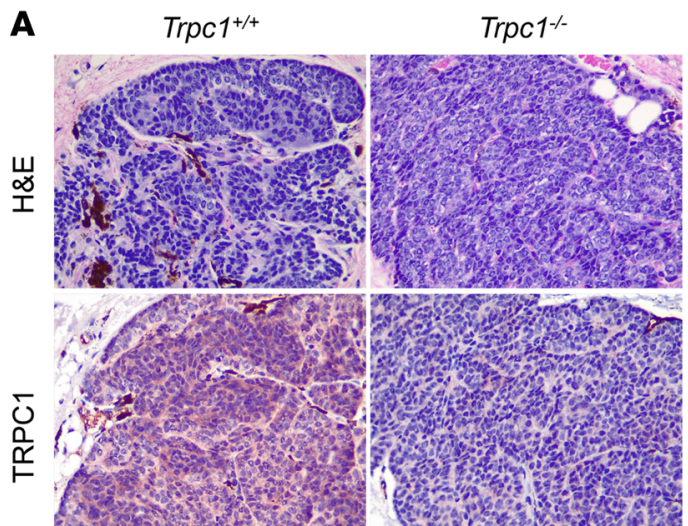

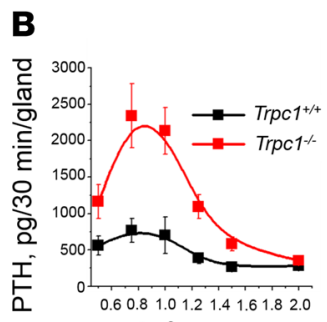

$\left[\mathrm{Ca}^{2+}\right]_{\mathrm{e}}, \mathrm{mM}$

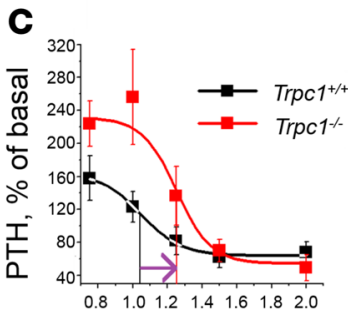

$\left[\mathrm{Ca}^{2+}\right]_{\mathrm{e}}, \mathrm{mM}$

Figure 2. Parathyroid glands lacking TRPC1 fail to properly control PTH secretion. (A) TRPC1 is widely expressed in normal mouse PTCs. Top: H\&E staining of $\operatorname{Trpc}^{1^{++}}$(left) and $\operatorname{Trpc1}^{-/-}$(right) glands. Bottom: Expression of TRPC1 in WT (left) and Trpc1-null (right) PTGs by immunohistochemistry using a mouse monoclonal antibody against TRPC1 (1F1). Original magnification, $\times 40$. (B) Responses of PTH release at different $\left[\mathrm{Ca}^{2+}\right]_{\mathrm{e}}(\mathrm{pg} / 30 \mathrm{~min} / \mathrm{gland})$ in PTGs isolated from 8 (3 males and 5 females) WT and 8 ( 3 males and 5 females) 14-week-old Trpc1-null mice. (C) $\mathrm{Ca}^{2+}$ dose-response curves shown in B were normalized and are expressed as a percentage of the PTH release at $0.5 \mathrm{mM} \mathrm{Ca}^{2+}$. Perpendicular lines depict $\mathrm{Ca}^{2+}$ set points (1.04 $\mathrm{mM} \pm 0.15$ for $\operatorname{Trpc}^{1^{+/}}$and $1.25 \mathrm{mM} \pm 0.08$ for $\operatorname{Trpc1}^{-/-}$mice).

TRPC1 $\alpha$ F689A, spermine activation of CaSR induced less intracellular $\mathrm{Ca}^{2+}$ accumulation than PTH-C1 cells coexpressing CaSR and WT TRPC1 $\alpha$ (Figure 3F). These data show that TRPC1 $\alpha$ has an essential and specific role in suppressing PTH secretion in PTH-C1 cells and this property involves its ability to conduct $\mathrm{Ca}^{2+}$.

TRPC1 overexpression suppresses PTH secretion. Next, we determined whether TRPC1 overexpression can suppress PTH secretion in PTH-C1 cells. Overexpression of WT TRPC1 $\alpha$, but not TRPC1 $\alpha$ F689A, suppressed PTH secretion in PTH-C1 cells (Figure 4A). We also compared side-by-side overexpression of CaSR (positive control) and 2 other highly expressed TRP channels in the PTG, TRPM4 or TRPM7 (Figure 4B), or WT STIM1, Orai1 and their constitutively active mutants, STIM1R304W and Orai1P245L (29). We chose to test the effect of WT and active mutants of STIM1 and Orail on PTH secretion because we have previously shown that TRPC1 functions together with these proteins to increase the dynamic range of SOCE channels (23). Overexpression TRPC1 $\alpha$ or CaSR suppressed PTH secretion (Figure 4A). Overexpression of TRPM4, TRPM7, STIM1, or Orai1 had no effect on PTH secretion, whereas overexpression of constitutively active STIM1 or Orai1 mutants increased PTH secretion. Knockdown of Orai1 did not affect PTH secretion. The positive effect of constitutively active STIM1/Orail mutants on PTH release is consistent with the well-known role of SOCE channels in hormonal release, exocytosis, and mast cell degranulation (30). These data provided additional evidence that TRPC1 has a specific, essential, and sufficient role in suppressing PTH secretion in PTH-C1 cells and does so independently of its ability to enhance SOCE.

TRPC1 functions downstream of CaSR in PTH-C1 or HEK293 cells. To test whether TRPC1 functions downstream of $\mathrm{CaSR}$ in $\mathrm{Ca}^{2+}$ signaling in $\mathrm{PTH}-\mathrm{C} 1$ cells, we transiently depleted TRPC1 in PTH-C1 cells using a rat $\operatorname{Trpc1}$-specific siRNA. Trpc1 mRNA translation is initiated by 2 alternative start sites. Translation initiation by an upstream leucine generates the long form of TRPC1, whereas initiation by a downstream methionine generates the short form of TRPC1. The 2 isoforms differ by N-terminal extension of 78 amino acids (23). PTH-C1 cells expressed predominantly the long form of TRPC1, which was downregulated in cells transfected by a rat Trpc1-specific siRNA (Figure 5A). Depletion of TRPC1 attenuated intracellular $\mathrm{Ca}^{2+}$ signaling in cells activated by extracellular $\mathrm{Ca}^{2+}$, spermine, or R-568 
A
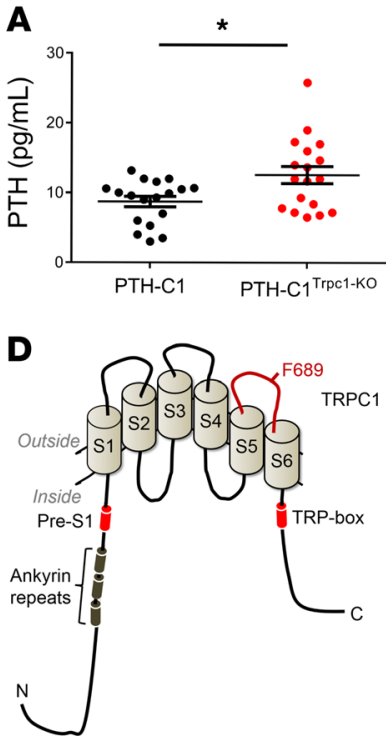

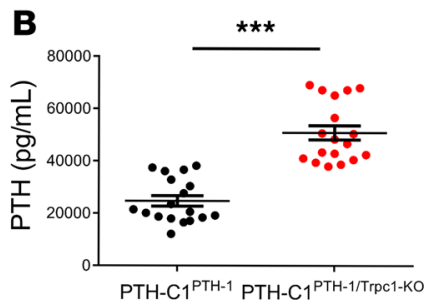

$\mathbf{E}$

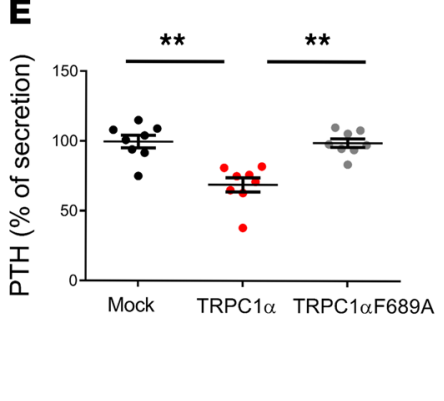

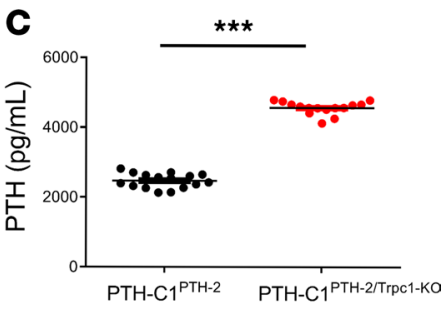

$\mathbf{F}$

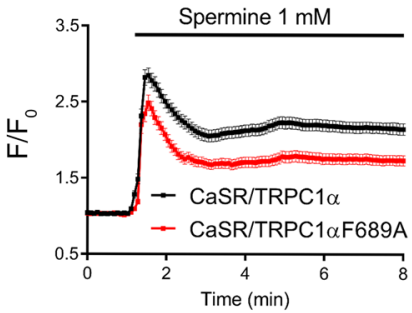

Figure 3. Inactivation of the Trpc1 gene increases PTH secretion. (A-C) Absolute PTH levels in media of WT PTH-C1 cells or cells lacking TRPC1 in the presence or absence of exogenously transfected PTH. ${ }^{*} P<0.05$; ${ }^{* *} P<0.001$, Student's $t$ test. (D) TRPC1 topology and location of F689. Pore-forming region connecting S5 and S6 is shown in red. Ankyrin repeats are shown as dark green cylinders and pre-S1 and TRP-box domains as shown are red cylinders. (E) Readdition of WT mouse TRPC1 $\alpha$ but not the TRPC1 $\alpha$ F689A pore mutant rescues suppressed PTH secretion in cells

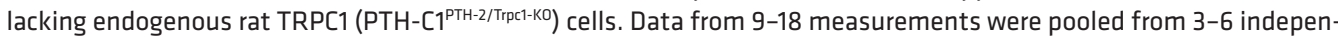
dent experiments. ${ }^{* *} P<0.01$, 1-way ANOVA. (F) Spermine-induced changes in free intracellular $\mathrm{Ca}^{2+}$ in $\mathrm{HEK} 293$ cells transiently cotransfected with CaSR plus WT TRPC1 $\alpha$ (black, $n=296$ cells pooled from 3 experiments) or TRPC1 $\alpha$-F689A (red, $n=276$ cells pooled from 3 experiments).

(Figure 5, B-E), which are all well-established activators of the CaSR (9). The response to spermine represented specific activation of CaSR, since it was completely blocked in the presence of the CaSR-specific inhibitor, NPS2143 (Figure 5D). These data showed that TRPC1 depletion reduced CaSR-induced $\mathrm{Ca}^{2+}$ signaling, consistent with the hypothesis that TRPC1 functions downstream of CaSR activation to increase intracellular $\mathrm{Ca}^{2+}$ concentration to suppress $\mathrm{PTH}$ secretion. Activation of CaSR can lead to the concurrent activation of both SOCE and ROCE channels. Our functional PTH secretion assays suggested that TRPC1 functions independently of SOCE channels in suppressing PTH secretion. Here, we used a heterologous system to test whether TRPC1 can be specifically coupled to CaSR and function independently of SOCE channels in $\mathrm{Ca}^{2+}$ signaling. To test for the contribution of TRPC1 in SOCE, HEK293 cells were transfected with TRPC1 and CaSR or m1 acetylcholine receptor (AchR), which is also coupled to $\mathrm{G} \alpha 11 / \mathrm{G} \alpha \mathrm{q}$, and stimulated with thapsigargin to deplete internal $\mathrm{Ca}^{2+}$ stores followed by direct activation of transfected CaSR or $\mathrm{m} 1 \mathrm{AchR}$ with spermine or carbachol, respectively. Expression of TRPC1 enhanced $\mathrm{Ca}^{2+}$ signaling in cells transfected with CaSR (Figure 5F) but not $\mathrm{m} 1 \mathrm{AchR}$ (Figure $5 \mathrm{G})$. In addition, overexpression of TRPC1 did not have an effect on thapsigargin-induced $\mathrm{Ca}^{2+}$ signaling. These data suggest that TRPC1 is coupled to CaSR via a mechanism independent of depletion of intracellular $\mathrm{Ca}^{2+}$ stores, supporting our data from PTH secretion assays in PTH-C1 cells, in which overexpression or knockdown of STIM1 or Orail did not affect PTH secretion.

Ga11 physically interacts with TRPC1 and increases its activity. Given the established role of Ga11 in FHH and PTH secretion (3), we asked whether G $\alpha 11$ overexpression could further enhance CaSR-induced TRPC1-mediated $\mathrm{Ca}^{2+}$ influx. Indeed, overexpression of $\mathrm{G} \alpha 11$ augmented TRPC1-mediated $\mathrm{Ca}^{2+}$ influx in response to spermine activation of CaSR in HEK293 cells using 2 different protocols (Figure 6, A and B). Ga11 could enhance TRPC1 activity by multiple mechanisms. One possible mechanism could involve complex formation of Ga11 with TRPC1, as previously reported for receptor-activated TRP channels and $G \alpha_{q}(31)$. Therefore, we examined whether $G \alpha 11$ could interact with TRPC1. We tested both long and short forms of TRPC1 $\alpha$ and TRPC1 1 isoforms. TRPC1 $\alpha$ is the most widely expressed form of TRPC1, whereas TRPC1 1 has a 7-amino acid deletion at the beginning of exon 5 corresponding to the N-terminal cytosolic domain of TRPC1 and, so far, is shown to be 

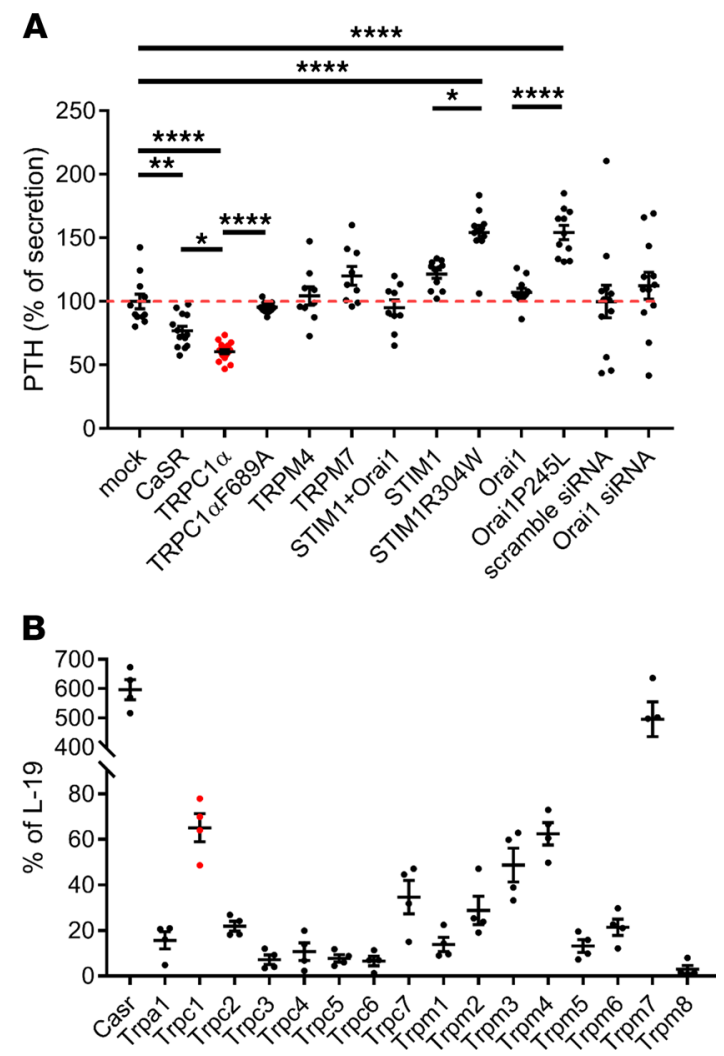

Figure 4. TRPC1 overexpression suppresses PTH secretion independently of SOCE and other TRP channels expressed in the mouse PTC. (A) Normalized levels of secreted PTH in media of PTH-C1 cells transiently transfected with indicated expression plasmids or siRNAs ( $n=9$ measurements pooled from 3 independent experiments). ${ }^{*} P<0.05 ;{ }^{* *} P$ $<0.005 ;{ }^{* *} P<0.001,{ }^{* * *} P<0.0001,1$-way ANOVA. (B) Expression levels of TRP channel mRNAs in mouse PTC by Affymetrix Mouse Microarray analyses. L-19 was used as the housekeeping gene ( $n=4$ batches of 20 PTCs).

expressed in myeloid precursor cells (23). Coimmunoprecipitation experiments in transiently transfected HEK239T cells followed by deletion analysis showed that either TRPC1 $\alpha$ or TRPC1 $\varepsilon$ isoforms interacted with Ga11 through their N- and C-termini (Figure 6, C and D). Consistently, endogenous TRPC1 colocalized with Ga11 in PTH-C1 cells (Supplemental Figure 6). In contrast, TRPC1 did not interact with $\mathrm{G} \alpha \mathrm{S}$, showing specificity of TRPC1 to G $\alpha 11$ (Figure 6, C and D). In light of genetic data in which inactivating mutations in GNA11 in humans produce a phenotype also seen in Trpc1-null mice, plus the molecular and functional data that show that $\mathrm{G} \alpha 11$ coimmunoprecipitates and enhances the activity of TRPC1, we propose that the direct interaction between TRPC1 and Ga11 potentiates the stimulatory effects of CaSR on TRPC1.

\section{Discussion}

The discovery of CaSR had a profound effect on our understanding how PTG cells sense extracellular $\mathrm{Ca}^{2+}$ levels $(2,6,9,32,33)$. However, there are still gaps in our knowledge regarding how PTG cells regulate PTH secretion downstream of CaSR. We provide in vivo, ex vivo, and in vitro evidence that TRPC1 functions downstream of CaSR to suppress PTH secretion. This information can help direct future studies to better our understanding of how the $\mathrm{Ca}^{2+}$ signaling can regulate $\mathrm{PTH}$ release, calcitonin secretion, and secretion of other hormones from cells with a functional CaSR.

Global deletion of $\operatorname{Trp} 1$ resulted in a phenotype that showed significant similarities to FHH $(21,34)$. Statistically, as a group, patients with FHH exhibit mild but significant hypercalcemia, while a few of them show elevated PTH $(5,35)$, similar to male $\operatorname{Trpc}^{1^{--}}$mice. Hypocalciuria, a hallmark of $\mathrm{FHH}$ not typically seen in primary hyperparathyroidism $(5,36)$, was also observed in our $\operatorname{Trp} 1^{-1-}$ mice. These data are consistent with the idea that TRPC1 functions downstream of CaSR in the PTG and the kidney. Unchanged $1,25(\mathrm{OH})_{2}$ vitamin D levels are observed in patients with $\mathrm{FHH}(34,37,38)$, which is corroborated in our 
A

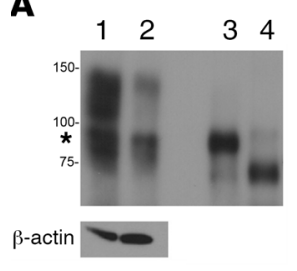

D
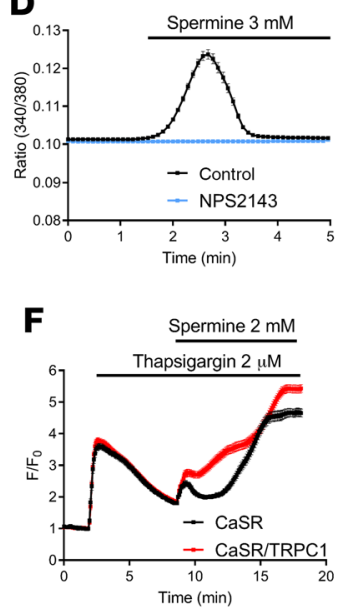

B

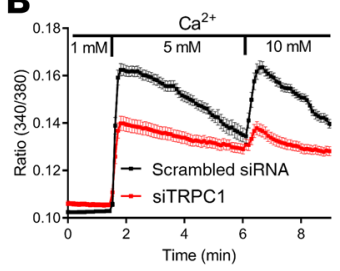

E

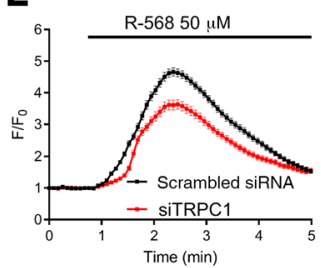

G

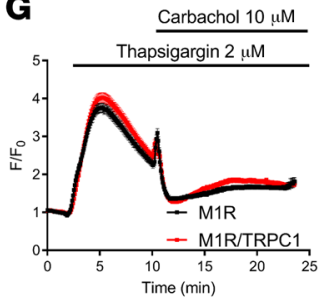

C

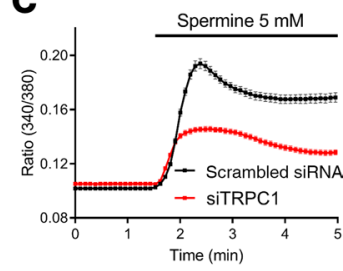

Figure 5. TRPC1 is required for CaSR-induced $\mathrm{Ca}^{2+}$ signaling in PTH-C1 cells. (A) Efficiency of TRPC1 knockdown using RNAi. PTH-C1 cells were transiently transfected with a scrambled siRNA (lane 1), siTRPC1 (lane 2), expression plasmid (positive control) of a long form of TRPC1 $\alpha$ (lane 3), or a short form of TRPC1 $\alpha$ (lane 4). TRPC1 was immunoprecipitated and immunoblotted with a TRPC1-specific monoclonal antibody (1F1). PTH-C1 cells express predominantly the long form of TRPC1 $\alpha$ (indicated by an asterisk). (B) Changes in intracellular $\mathrm{Ca}^{2+}$ concentration (expressed as fluorescence ratio 340/380) in PTH-C1 cells transiently transfected with a scrambled siRNA (control, black, $n=76$ cells pooled from 5 independent experiments) or a Trpc1-specific siRNA (siTRPC1, red, $n=61$ cells pooled from 6 independent experiments) and cultured in 1, 5, or $10 \mathrm{mM}$ extracellular $\mathrm{Ca}^{2+}$. (C) Time course of spermine-induced (5 mM) intracellular $\mathrm{Ca}^{2+}$ concentration in PTH-C1 cells transiently transfected with a scrambled siRNA (control, black, $n=144$ cells pooled from 4 independent experiments) or a Trpc1-specific siRNA (siTRPC1, red, $n=178$ cells pooled from 8 independent experiments). (D) Time course of intracellular $\mathrm{Ca}^{2+}$ concentration in PTH-C1 cells cultured in 0 extracellular $\mathrm{Ca}^{2+}$ and activated by spermine ( $3 \mathrm{mM}$ ) in the presence (blue, $n=279$ cells from 6 experiments) or absence of NPS2143 ( $300 \mathrm{nM}$ ) (black, $n=233$ cells from 5 experiments). (E) Time course of R568-induced $(50 \mu \mathrm{M})$ intracellular Ca $\mathrm{a}^{2+}$ concentration in PTH-C1 cells transiently cotransfected with GCaMP3 and scrambled siRNA (control, black line, $n=216$ cells pooled from 9 independent experiments) or TRPC1 siRNA (siTRPC1, red line, $n=172$ cells pooled from 9 independent experiments) in the presence of $1.8 \mathrm{mM}$ extracellular $\mathrm{Ca}^{2+}$ concentration. $\mathrm{F}_{0}$ was the average fluorescence for 1 minute prior to the addition of $\mathrm{R}-568$. (F and G) TRPC1 is specifically coupled to CaSR. HEK293 cells were transiently cotransfected with GCaMP3, CaSR (F), or $\mathrm{m} 1$ muscarinic acetylcholine receptor ( $\mathrm{m} 1 \mathrm{AchR}, \mathbf{C})$ in the presence or absence of TRPC1 (red or black traces). Cells were first stimulated with thapsigargin $(2 \mu \mathrm{M})$ to deplete the internal stores and then with spermine $(2 \mathrm{mM}, \mathbf{F})$ or carbachol $(10 \mu \mathrm{M}, \mathbf{C})$ to activate CaSR or $\mathrm{m} 1 \mathrm{AchR}$, respectively. Changes in intracellular free $\mathrm{Ca}^{2+}$ concentration are reported as $\mathrm{F} /$ $F_{0}$. Data were pooled from 6 independent experiments totaling 263 cells transfected with CaSR (black, F) and 316 cells transfected with CaSR plus TRPC1 (red, F) or from 8 independent experiments totaling 190 cells transfected with $\mathrm{m} 1$ AchR (black, G) and 173 cells transfected with m1 AchR plus TRPC1 (red, G).

$\operatorname{Trpc1^{-/-}}$ mice. A few differences are noteworthy between $\operatorname{Trpc1}^{-/-}$mice and patients with FHH. Serum $\mathrm{Mg}^{2+}$ is often moderately increased in some patients with $\mathrm{FHH}(3,4,39)$, but $\mathrm{Mg}^{2+}$ levels were normal in $\operatorname{Trpc1^{-/-}}$ mice. Second, Trpc1 $1^{-/-}$mice and mice with kidney-specific deletion of Casr have normal serum phosphorous levels (40), unlike patients with FHH with reduced levels (35). Finally, there are changes in skeletal manifestation between our mice and patients with $\mathrm{FHH}$. In FHH, bone mass is generally comparable to that of normal controls $(20,21,41)$. However, our Trpc1-null mice had substantially increased and progressive changes in bone mass with age. Indeed, previously we reported significantly decreased osteoblast number per bone surface and reduced osteoclast numbers per bone surface in histomorphometric assays of 3-month-old Trpc1-null mice (23). These similarities and differences may correlate to compensatory proteins that differ between mice and humans in the kidney, PTG, and bone cells. With the exception of $\mathrm{Casr}^{+/-}$mice (42) and a newly described mouse model carrying a loss-of-function mutation (D195G) in 
A

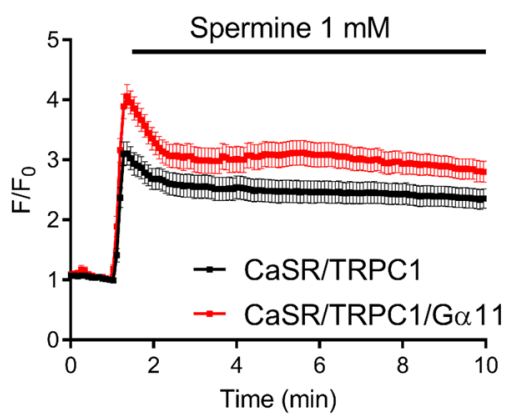

C
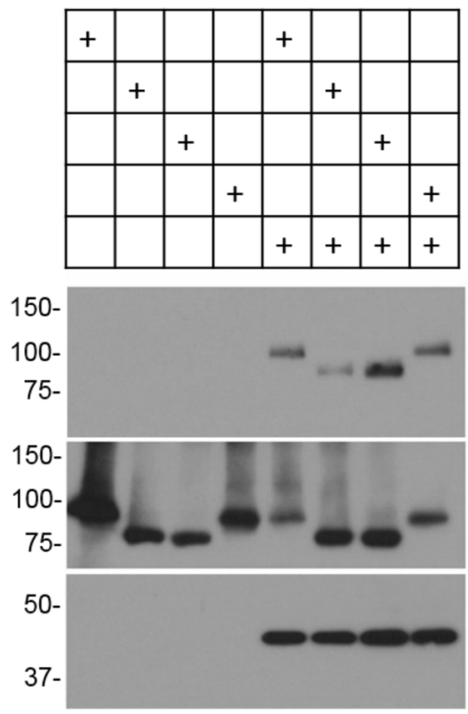

TRPC1 $\alpha$ (long)

TRPC1 $\alpha$ (short)

TRPC1 $\varepsilon$ (short)

TRPC1 1 (long)

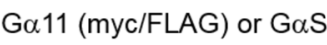

IP: $\alpha-m y c$

IB: $\alpha$-TRPC1

IB: $\alpha$-TRPC1

IP: $\alpha-$-myc

IB: $\alpha$-myc

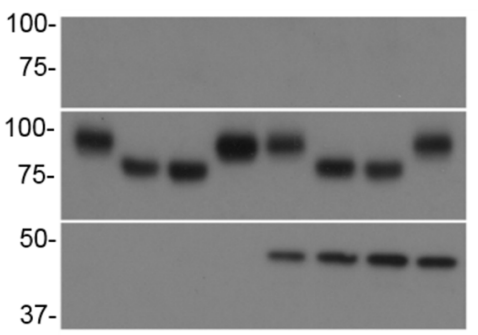

IP: $\alpha-G \alpha S$

IB: $\alpha$-TRPC1

IB: $\alpha$-TRPC1

IP: $\alpha-G \alpha S$

IB: $\alpha-G \alpha S$

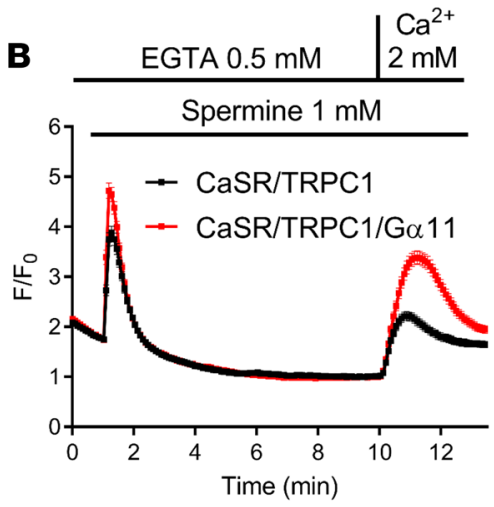

D

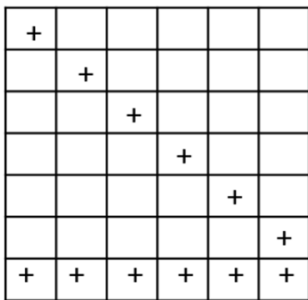

GST

$\mathrm{N}(\alpha)$-ter (GST)

$\mathrm{N}(\varepsilon)$-ter (GST)

$\Delta \mathrm{N} \Delta \mathrm{C}$ (GST)

C-ter (GST)

$\triangle N(G S T)$

Ga11 (myc/FLAG) or G $\alpha$ s

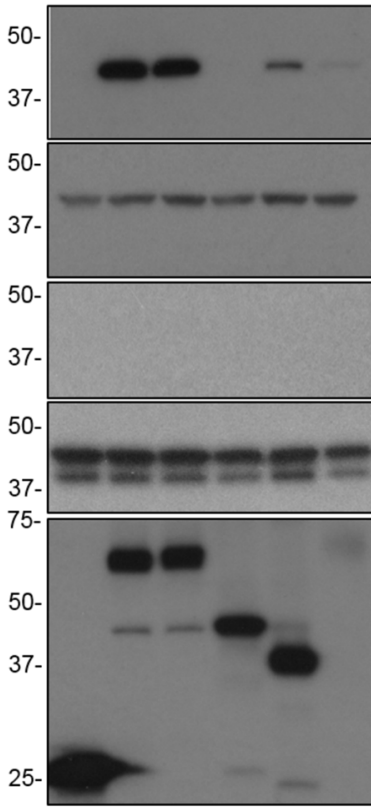

IP: $\alpha-G S T$

IB: $\alpha-G \alpha 11-F l a g$

IB: $\alpha-G \alpha 11-F l a g$

IP: $\alpha-G S T$

IB: $\alpha-G \alpha s$

IB: $\alpha-G \alpha s$

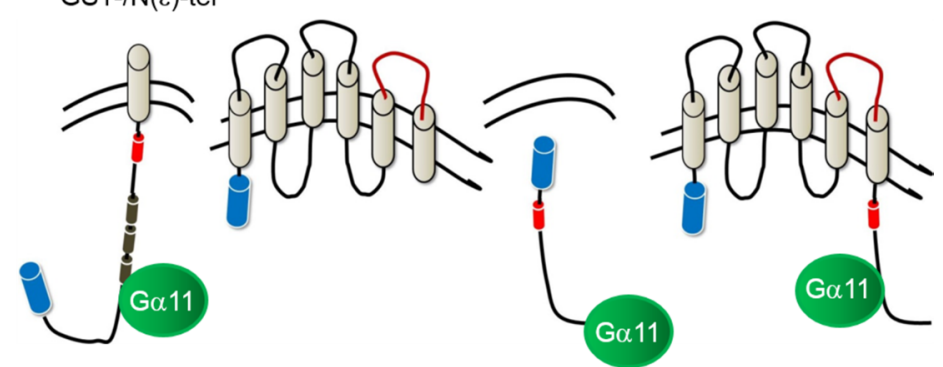

Figure 6. Ga11 physically interacts with TRPC1 and increases its activity. (A and B) Ga11 increases TRPC1-mediated Ca²+ signaling in HEK293 cells. Cells were transiently transfected with CaSR and TRPC1 $\alpha$ or CaSR, TRPC1 $\alpha$, and G $\alpha 11$. Both groups were cotransfected with the fluorescent $C a^{2+}$ indicator, GCaMP3, and fluorescence intensity was determined by single-cell $\mathrm{Ca}^{2+}$ imaging. Changes in intracellular $\mathrm{Ca}^{2+}$ concentration $\left(\mathrm{F} / \mathrm{F}_{0}\right)$ in response to spermine $(1 \mathrm{mM})$ were determined under physiological conditions $\left(1.8 \mathrm{mM}\right.$ extracellular $\left.\mathrm{Ca}^{2+}, \mathbf{A}\right)$ or in $\mathrm{Ca}^{2+}$ free ECS followed by Ca ${ }^{2+}$ readdition (2 mM, B). Data were pooled from 74 (black) or 85 (red) cells from 2 independent transfections (A) and 318 (black) or 261 (red) cells from 4 independent transfections (B). (C) 


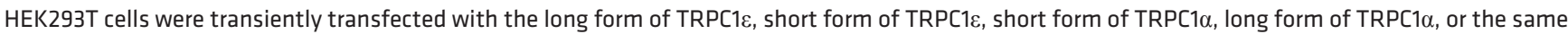
TRPC1 plasmids plus myc-tagged G $\alpha 11$ (top 3 rows) or $\mathrm{G} \alpha \mathrm{S}$ (bottom 3 rows). G $\alpha 11$ was immunoprecipitated using $\alpha$-myc, and $\mathrm{G} \alpha \mathrm{S}$ was immunoprecipitated using $\alpha-\mathrm{G} \alpha \mathrm{S}$. TRPC1 was detected in the complexes using anti-TRPC1 (top). TRPC1 input is shown in middle panels, and immunoprecipitated Ga11 or G $\alpha \mathrm{S}$ is shown in bottom panels. (D) Truncation mutants of TRPC1 $\alpha$ (CST alone, GST-N $(\alpha)$-ter, GST-N( $\varepsilon$ )-ter, GST- $\Delta N \Delta C$, GST-C-ter, GST- $\Delta N$ ) shown in E tagged with GST (blue cylinders) were cotransfected with WT G $\alpha 11$ or G $\alpha$ S. Protein-protein interactions were determined by GST pulldowns followed by immuno-

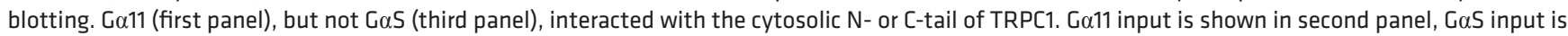
shown in fourth panel, and immunoprecipitated mutants of TRPC1 are shown.

Gna11 (43), which recapitulates human FHH both at the disease phenotypic and genetic levels, there are no other suitable mouse models for $\mathrm{FHH}$, including orthologous mouse models. For example, while dominant loss-of-function mutations in GNA11 result in FHH in patients (3), homozygous global deletion of Gna11 in the mouse did not produce a significant phenotype (44). The PTG-specific deletion of Gnaq combined with global deletion of Gna11 recapitulated some aspects of $\mathrm{FHH}$ in the mouse (45), suggesting potential gene redundancy by Gnaq in the mouse but not in humans. Alternatively, dominant negative effects of lossof-function alleles of Gna11 could be implicated in FHH. Nevertheless, the generation of additional mouse models of FHH could help advance our understanding of the pathophysiology of $\mathrm{FHH}$ and diseases of the PTG. We believe that the global Trpc1-KO mouse model presented here can be considered as a suitable mouse model for $\mathrm{FHH}$ because it recapitulates several key features of $\mathrm{FHH}$. Additional refinements could be made by the tissue-specific deletion of Trpc1 in the PTG, bone, and kidney.

Our data suggest that Ga11-mediated signaling downstream of CaSR couples serum $\mathrm{Ca}^{2+}$ concentration and PTH secretion. CaSR is linked to several classes of $\mathrm{G} \alpha$ subunits and it remains unknown which subclass(es) and how specific G protein(s) mediate the CaSR's effects on PTH secretion (9). The identification of naturally occurring mutations in GNA11 in patients with FHH2 strongly suggests that the G $\alpha 11 / \alpha q$ subclass conveys the signal to suppress PTH secretion following activation of CaSR (3). Our data support this hypothesis and further identify the ion channel mediating such an effect. While we favor the idea that TRPC1 is a direct target of activated Ga11, we cannot rule out a possible modulation of TRPC1 activity by other $\mathrm{G} \alpha$ subclasses coupled to CaSR, either directly via protein-protein interactions or indirectly via cAMP/PKA-mediated signaling (Gai/o) and regulation of the actin cytoskeleton $(\mathrm{G} \alpha 12 / 13)$. The FHHlike phenotype we observed in Trpc1-null mice is less severe than the phenotype produced by the deletion of CaSR in mice $(22,42)$, suggesting that loss of TRPC1 in the PTG produces a milder phenotype than the loss of CaSR signaling. While other $\mathrm{G} \alpha 11$-activated $\mathrm{Ca}^{2+}$-permeable channels can work in parallel with TRPC1 to suppress PTH secretion, $\mathrm{Ca}^{2+}$-independent signaling could also account for the remaining effect of PTH suppression in Trpc1-null cells/tissues. Alternatively, TRPC1-mediated $\mathrm{Ca}^{2+}$ signaling may have a permissive role in the suppression of PTH secretion under conditions of abnormally high serum $\mathrm{Ca}^{2+} 1 \mathrm{ev}$ els. Regardless of the exact mechanism by which TRPC1 influences PTH secretion and the extent to which it contributes to the overall effect of CaSR on PTH secretion, our studies identify what is probably the first ion channel that can function downstream of CaSR in the control of PTH secretion and, thus, can spur new studies on the role of $\mathrm{Ca}^{2+}$ signaling in $\mathrm{PTH}$ homeostasis.

While TRPC1 was the first mammalian TRP channel identified more than 20 years ago (46), its activation mechanism remains unclear (13). Our studies identifying TRPC1 as part of the cellular apparatus controlling PTH secretion have implications in its activation mechanisms. We had shown earlier that TRPC1 can be activated by store depletion (23), but our PTH secretion data in PTH-C1 cells show that activation by store depletion could not account for its effect on PTH secretion. This conclusion is based on PTH secretion data, whereby overexpression or depletion of STIM1 or Orai1 did not affect PTH secretion in PTH-C1 cells and, furthermore, overexpression of constitutively active STIM1 and Orai1 identified in patients with Stormorken or a Stormorken-like syndrome, respectively, enhanced rather than suppressed PTH secretion. While this seems to be at odds with mild hypocalcemia reported in some patients with Stormorken (47), it is in agreement with the well-established role of SOCE channels in exocytosis and hormonal release (30). The hypocalcemia seen in patients with Stormorken could be due to secondary effects of STIM1R304W in tissues other than the PTG, such as the kidney or bone. More studies are necessary to determine the effect of STIM1R304W or Orai1P245L on hypocalcemia.

We show that overexpression of Ga11 increases TRPC1-mediated $\mathrm{Ca}^{2+}$ influx and $\mathrm{G} \alpha 11$ physically interacts with both the $\mathrm{N}$ - and C-terminus of TRPC1. We propose that TRPC1 can be directly activated by a physical interaction with $G \alpha 11$. Our data do not favor the idea that freed G $\beta \gamma$ complex mediates an effect 
on TRPC1, because inhibition of G $\beta \gamma$ complex with Gallein did not affect PTH secretion in PTH-C1 cells (our unpublished observations). Direct Gaq-mediated regulation of TRP channels was first described in the Drosophila TRPL channel (31), which shows the closest homology to members of the TRPC subgroup of mammalian TRP channels. Recently, TRPC4 or TRPC5 was shown to physically interact with Gaq, which is structurally related to Ga11 (48). We have shown that TRP channels, including the canonical group (TRPC1-7), require an intramolecular interaction between their N- and C-termini during activation (49). This intramolecular interaction is influenced by levels of membrane phospholipid, $\mathrm{PIP}_{2}$, and mediated by a tryptophan residue in the pre-S1 domain and an arginine residue in the TRP-box domain in the C-terminal tail. It would be interesting to know whether interaction of TRCP1 and G 11 involves these domains. Nevertheless, because G $\alpha 11$ interacted with both the N- and C-terminus of TRPC1 and overexpression of G $\alpha 11$ increased TRPC1 activity, we speculated that a physical interaction with G $\alpha 11$, following PIP ${ }_{2}$ breakdown would stabilize the N-/C-interaction causing faster activation of TRPC1.

In summary, our data identify TRPC1 as one of the channels mediating a critical step in the suppression of PTH secretion in response to a rise in serum $\mathrm{Ca}^{2+}$. Information generated by our studies could be useful in designing new and more effective therapeutic approaches for diseases of the PTG by targeting molecules downstream of CaSR.

\section{Methods}

Mice

Mice were maintained under pathogen-free condition in the barrier facility of University of Oklahoma Health Sciences Center. WT (Trpc1 $\left.{ }^{+/+}\right)$and $\operatorname{Trpc1}^{-/-}$mice were on a pure 129/SvEv background (19).

Cell culture

PTH-C1 cells, a cell line derived from rat PTG, were a gift from Maria Luisa Brandi (FirmoLab, Università degli Studi di Firenze) and cultured in prescribed conditions (26). HEK293 and HEK293T cells were purchased from ATCC and cultured in DMEM (Corning; 10-013) enriched by 10\% FBS (Atlanta Biologicals; S11550).

\section{In vivo studies}

Collection of blood, urine, and clearance samples. Mice were weighed every 7-10 days. Studies were performed on mutant $\left(\operatorname{Trp} c 1^{-/-}\right)$and littermate controls $\left(\operatorname{Trp} c 1^{+/+}\right)$from 3.5 to 21.5 months of age. Twenty-four-hour urine was collected at various times over 21.5 months in individual metabolic cages. A trace amount of sugar was added to drinking water to promote ingestion and to increase urine volume in order to optimize the completeness of collection, as verified by daily creatinine excretion. Water and food intake was monitored during the balance studies. Blood was collected by tail bleed, fasted or unfasted, whichever appropriate, periodically from age 7 to 21.5 months, usually synchronized with metabolic urine collections, as appropriate. Renal clearance was performed in individual mice at 21.5 months to measure $\mathrm{Ca}^{2+}$ in urine directly collected from urinary bladder via indwelling catheters and to measure glomerular filtration rate by intravenously infused inulin using methods we established, as described earlier (50).

Measurements of creatinine, $\mathrm{Ca}^{2+}$, and $\mathrm{Mg}^{2+}$ in urine and blood and analysis of blood PTH, calcitriol, and calcitonin

Creatinine was measured by HPLC (Buck Scientific). $\mathrm{Ca}^{2+}$ was measured using Ca Arsenazo III dye adapted for a plate reader (Pointe Scientific). $\mathrm{Mg}^{2+}$ was measured using Arsenazo dye (Thermo Scientific Fisher). PTH was measured using a Mouse PTH 1-84 ELISA kit (Immunotopics). Mouse calcitriol (or 1,25-dihydroxyvitamin D) and calcitonin were measured using ELISA kits (Mybiosource, catalog MBS816417 and MBS026850, respectively).

\section{RNA interference}

PTH-C1 cells were cultured to 70\% confluency and transfected with siTRPC1 (Dharmacon; L-08012802-0005) or siOrai1 (Dharmacon; L-081151-02-0005) or nontargeting siRNA (Dharmacon; D-001810-1005) using Lipofectamine3000 (Invitrogen). Two days after transfection, cells were transferred into 24-well plates for PTH secretion analysis or 18-mm glass disks for single-cell $\mathrm{Ca}^{2+}$ imaging analysis. 


\section{CRISPR/Cas9}

Exon 1 of the rat Trpc1 locus was edited using CRISPR/Cas9 and the following guide: (T2) 5'-CACCGGGCGCTGAAGGATGTGCGAG-3' or (T3) 5'-CACCGGGCGGCCCTGTACCCGAGCA-3'. The Trpc1-specific sgRNA (T2) was cloned into lentiCRISPRv2 puro vector (Addgene) and used to transfect PTH-C1 cells. Puromycin-resistant stable clones were obtained and expanded, and gene editing of the Trpc1 locus was determined by Sanger sequencing.

\section{Patients and DNA sequence analysis}

Nineteen unrelated patients with FHH in whom previous mutational analysis of CASR, GNA11, and AP2S1 genes by Sanger DNA sequencing had not identified any abnormalities of the coding regions and exon-intron boundaries, were analyzed. DNA sequence analyses, using Sanger sequencing, of TRPC1 exons 1-12 of transcript ENST00000273482 and their adjacent splice sites were performed using leucocyte DNA and gene-specific primers (MilliporeSigma) (Supplemental Table 1), as previously reported (24). WES was performed using leucocyte DNA, as previously described (4). Publicly accessible databases were examined for the presence of sequence variants, including dbSNP (http://www.ncbi.nlm.nih.gov/projects/SNP/); 1000 genomes (https:// www.internationalgenome.org/home); the National Heart, Lung and Blood Institute Exome Sequencing Project (http://evs.gs.washington.edu/EVS/, EVS data release ESP6500SI), representing the exomes of approximately 6500 individuals; and the gnomAD v2.1.1 database (https://gnomad.broadinstitute.org/), representing 125,748 exomes and 15,708 genomes of unrelated individuals mapped to the GRCh37/hg19 reference sequence.

\section{Expression plasmids}

Mouse PTH (MR200486) and Gna11 (MR205495) cDNAs were purchased from Origene. Human Orai1 (BC015369), mouse STIM1 (BC021644), and mouse TRPC1 $\alpha$ or TRPC1ع (CA327829) were obtained from Open Biosystems, as described earlier (23). TRPM4 and TRPM7 cDNAs were obtained from A. Scharenberg (University of Washington, Seattle, Washington, USA).

\section{Single cell $\mathrm{Ca}^{2+}$ imaging}

Fura2/AM labeling. PTH-C1 cells were plated onto glass coverslips and loaded with $2 \mu \mathrm{M}$ Fura-2/AM in extracellular solution (ECS) containing $140 \mathrm{mM} \mathrm{NaCl}, 5 \mathrm{mM} \mathrm{KCl}, 1 \mathrm{mM} \mathrm{MgCl}, 1.8 \mathrm{mM} \mathrm{CaCl}_{2}, 10 \mathrm{mM}$ glucose, and $15 \mathrm{mM}$ HEPES, pH $7.4\left(\left[\mathrm{Ca}^{2+}\right]_{0}: 1.8 \mathrm{mM}\right.$ ) in the presence of $0.05 \%$ Pluronic F-127 (ThermoFisher catalog P3000MP) for 45 minutes at room temperature. Cells were washed twice in ECS and incubated for 15 minutes in $37^{\circ} \mathrm{C}$ before intracellular imaging. Cells were incubated in ECS (Figure 5, B and C) or a $\mathrm{Ca}^{2+}$ free solution (same as ECS but without $\mathrm{CaCl}_{2}$ ) (Figure 5D) and stimulated with extracellular $\mathrm{Ca}^{2+}$ (Figure 5B) or spermine (Figure 5, C and D) at the indicated times. Individual cells were excited by the DeltaRam X monochromator (Photon Technology International), and emission images were collected by a high-definition imaging scientific CMOS camera driven by the EasyRatioPro software (Photon Technology International). Fluorescence ratios of 340/380 were taken every 5 seconds using a 30-millisecond exposure time. Intracellular $\mathrm{Ca}^{2+}$ concentration was expressed as $340 / 380$ ratio.

GCaMP3 labeling. PTH-C1 (Figure 6E) or HEK293 cells (Figure 3F; Figure 5, F and G; and Figure 6, A and B) were transfected with GFP-based calcium sensor for imaging calcium dynamics (GCaMP3). GCaMP3 was a gift from Loren Looger (Addgene plasmid, catalog 22692). Two days after transfection, cells were processed for single-cell $\mathrm{Ca}^{2+}$ imaging as described for Fura2/AM-labeled cells, but excitation was set at $474 \mathrm{~nm}$ and emission at $510 \mathrm{~nm}$. Fluorescence intensity was acquired every 5 seconds for 100 milliseconds, and intracellular $\mathrm{Ca}^{2+}$ concentration was expressed as the ratio of fluorescence signal at any given time point over baseline fluorescence $\left(\mathrm{F}_{0}\right.$, average fluorescence intensity before the addition of drug $)\left(\mathrm{F} / \mathrm{F}_{0}\right)$.

\section{Ex vivo secretion of PTH}

Sixteen-week-old mice were euthanized and PTGs were extracted. PTH secretion was performed as previously described (23). Glands were immediately transferred into $500 \mu 1$ inhibition buffer solution ( $3 \mathrm{mM}$ $\mathrm{Ca}^{2+}, 0.5 \mathrm{mM} \mathrm{Mg}{ }^{2+}, 0.2 \%$ BSA, 20 mM HEPES/MEM-EBSS-CMF, pH 7.4) and kept on ice. Next, glands were transferred onto $0.1 \mu \mathrm{M}$ Nucleopore Track-Etch Membrane (Whatman; 110405) and equilibrated in inhibition solution for 1 hour in a $37^{\circ} \mathrm{C} / 5 \% \mathrm{CO}_{2}$ incubator. Membranes with glands were transferred in buffer solutions $(500 \mu \mathrm{l})$ containing $0.5,0.75,1,1.25,1.5,2$, or $3 \mathrm{mM} \mathrm{Ca}^{2+}$ for 30 minutes. Secreted PTH was determined using the Mouse PTH 1-84 ELISA Kit (Immutopics; 60-2305). 


\section{In vitro secretion of PTH}

Secreted PTH from native and transiently or stably transfected PTH-C1 cells was determined using a Rat Intact PTH ELISA Kit (Immutopics; 60-2500). PTH was collected after 4-hour incubation in fresh secretion media solution (0.5 mM Ca ${ }^{2+}, 0.5 \mathrm{mM} \mathrm{Mg}^{2+}, 0.2 \%$ BSA, 20 mM HEPES/MEM-EBSS-CMF, pH 7.4) prior to quantification of PTH.

\section{PCR}

PTH-C1 cells were collected in TRIzol (Invitrogen; 15596026). RNA isolation was performed according to the manufacturer's instructions. Five $\mu \mathrm{g}$ RNA was used for reverse transcription. mRNA was combined with oligo (dT) 12-18 primer (Invitrogen; 18418012) and random hexamers (Invitrogen; N8080127) and incubated for 10 minutes in $70^{\circ} \mathrm{C}$. Next, $5 \times$ buffer, $0.5 \mu \mathrm{M}$ dNTP, $10 \mathrm{mM}$ DTT, and $20 \mathrm{U} / \mu 1$ SuperScript III were added (reverse transcription kit 18080093 from Invitrogen) and reaction was performed under the following conditions: $42^{\circ} \mathrm{C}$ for 45 minutes, $52^{\circ} \mathrm{C}$ for 30 minutes, and $70^{\circ} \mathrm{C}$ for 15 minutes. Primers used for further PCR were as follows: TRPC1 forward, GAGTTACCTTCGGCTCTTCTTT, reverse, GCTGAGGCTGCTGATCATATAG; nested forward, GCTCTGTTCTGGTACATCTTCTC, reverse, GGCAGTGTGCATTTGTCATC; TRPC4 forward, GAATGCTCCTGGACATCCTAAA, reverse, CCTCATCACCTCTTGGTATTGG; nested forward, GGTTAAGCTGCAAAGGCATAC, reverse, CCAAAGCTTTCTGGCTTTCTTC; TRPC5 forward, CAAGGTCCCGACTGAACATATAC, reverse, GCATGAAGAGGAAGGTCAGATAG; and nested forward, CTTCGCTCATCGCCTTATCA, reverse, ATGCTGTGTGGCAGATGAA.

\section{Affymetrix Mouse Microarray analyses}

For RNA expression in mouse PTGs, 4 batches of glands (PTGs) were dissected free of thyroid and the surrounding fibrous tissues and used for RNA extraction with a RNA-Stat 60 kit (Thermo Fisher Scientific) as described previously (25). The RNA was reversed transcribed into cDNA, which was then subjected to Affymetrix Mouse GeneChip Microarray analyses by the Genome Technologies Core Facility (University of Manchester) and Genome Analyses Microarray Core (University of California, San Francisco). The gene array data were analyzed using Affymetrix Genechip Software for an intensity value and normalized and presented as a percentage of the expression level of a mitochondrial microsomal protein L19 and used for statistical analyses $(n=4$ batches of RNA with each batch extracted from 20 PTGs dissected from 10 of 6-week-old C57bB6 mice).

\section{Coimmunoprecipitation}

PTH-C1 or HEK293T cells were lysed in native lysis solution (1\% Triton X-100, $150 \mathrm{mM} \mathrm{NaCl}, 10 \mathrm{mM}$ Tris-HCl, pH. 7.5, 1 mM EDTA, 1 mM EGTA, 0.5\% Igepal, $10 \%$ sucrose, $5 \mathrm{mM} \mathrm{NaF,} 200 \mu \mathrm{M}$ vanadate, protease inhibitor) in $4^{\circ} \mathrm{C}$ for 30 minutes. Cleared lysates were collected and used for coimmunoprecipitations. Myc- or GST-tagged proteins were captured using a rabbit monoclonal antibody against myc tag (clone 71D10, Cell Signaling; 2278) or Glutathione Sepharose 4B (GE Healthcare; GE17-0756-01), respectively. TRPC1 was detected using 1F1 (51), GaS (Santa Cruz; sc-135914), or GST (Santa Cruz; sc-459). Ga11 was detected using FLAG antibody (clone M2, MilliporeSigma; F1804).

\section{Immunohistochemistry staining for mouse PTG}

Four-micron-thick histological sections, embedded in paraffin and mounted on HistoBond Plus slides (Statlab Medical Products), were rehydrated and washed in Tris-buffered saline. The sections were processed for immunohistochemistry using M.O.M. (Mouse on Mouse ImmPRESS Peroxidase Polymer kit, Vector Labs) or, for rabbit antibodies, the ImmPRESS -VR Horse Anti-Rabbit IgG Polymer Peroxidase kit (Vector Labs). Antigen retrieval ( $\mathrm{pH} 6$ Citrate Antigen Unmasking Solution, Vector Labs) was accomplished via 20 minutes in a steamer followed by 30 minutes cooling at room temperature. Sections were treated with a peroxidase blocking reagent (Bloxall, Vector Laboratories)

\section{Double indirect immunofluorescence labeling}

PTH-C1 and PTH-C1 $1^{\text {Trpcl-KO }}$ cells seeded on coverslips were fixed with cold methanol for 5 minutes in room temperature and then washed 3 times with ice-cold PBS. Cells were permeabilized with $0.5 \%$ Saponin solution for 10 minutes followed by 3 washes in PBS. Blocking was done with 3\% BSA for 15 minutes, and then cells were incubated with primary antibody (TRPC1-1F1, 1:500, Ga11 1:200) diluted in 
$1 \% \mathrm{BSA}$ in $4^{\circ} \mathrm{C}$ overnight. Secondary antibodies coupled to Alexa Fluor 488 (Thermo Scientific Fisher; A11029, used at 1:2,000 dilution) or Alexa Fluor 594 (Thermo Scientific Fisher; A11012, used at 1:2,000 dilution) were added on coverslips for 2 hours at $4^{\circ} \mathrm{C}$ followed by 3 washes in PBS. Coverslips were mounted with Diamond DAPI solution (ProLong Diamond Antifade Mountant with DAPI, Thermo Scientific Fisher; P36962). Images were acquired and processed with laser scanning confocal microscope (Olympus Fluoview 1000) in an inverted configuration.

\section{Statistics}

All experiments showing protein-protein interactions and indirect immunofluorescence staining were repeated at least 3 times. Data measurements were presented as mean value \pm SEM. Differences between 2 groups were determined by unpaired, 2-tailed Student's $t$ test or Mann Whitney test (if data within groups fail to show normal distribution as determined by the D'Agostino-Pearson normality test). Significant differences between more than 2 groups were determined by 1- or 2-way ANOVA, as indicated followed by Sidak's multiple comparison test or Kruskal-Wallis test followed by Dunn's multiple comparison test (if data failed the D'Agostino \& Pearson normality test). All statistical analyses were performed using GraphPad Prism 7 software. $P$ values of less than 0.05 were considered significant.

To establish whether our analysis was sufficiently powered to detect at least 1 TRPC1 mutation with a greater than 95\% likelihood, the sample size required was determined by binomial probability analysis (Microsoft Excel), as previously reported (24). Approximately $65 \%$ of patients with FHH1 have a CASR mutation (52), and for this binomial analysis the prevalence for TRPC1 mutations in patients with FHH without $C A S R$, GNA11, or $A P 2 S 1$ mutations was set at $20 \%$, and a similar approach to that described for a search of $A P 2 S 1$ mutations in $\mathrm{ADH}$ patients was used (24). The binomial distribution probability was calculated using the following formula: binomial distribution probability $=b(x ; n, p)$, where $b(x ; n, p)=(n x) p x(1-p) n-x$, where $n$ indicates sample size, $x$ represents the number of probands harboring mutations; $n-x$ denotes the number of probands with no mutation; and $p$ represents the prevalence of TRPC1 mutations in the cohort.

\section{Study approval}

All procedures were approved by the IACUC of University of Oklahoma Health Sciences Center (301163 OUHSC IACUC original protocol approval_18-101_11/7/2018\#18-101). Informed consent was obtained from individuals using protocols approved by the multicentre research ethics committee (MREC), London, United Kingdom, (approval code MREC/02/2/93).

\section{Author contributions}

$\mathrm{MO}, \mathrm{VN}$, and $\mathrm{LT}$ performed and analyzed in vitro experiments. $\mathrm{MO}, \mathrm{PN}, \mathrm{BE}$, and $\mathrm{KL}$ performed and analyzed in vivo experiments. $\mathrm{MO}, \mathrm{MBH}$, and WC performed ex vivo experiments. ML performed immunohistochemistry staining studies. MLB provided critical reagents. CMG, VJS, and RVT acquired and analyzed human DNA-sequencing data. MO and LT wrote the manuscript with the help of MBH and KL. LT oversaw the project.

\section{Acknowledgments}

This work was supported by NIH grant R01 AR064211 (to LT and MBH), the Presbyterian Health Foundation (to MBH), NIH grant R01 DK12165601 (to LT and WC), US Department of Veterans Affairs Biomedical Laboratory Research and Development grant I01BX003453 (to WC), the FIRMO Foundation (to MLB), a Wellcome Trust Investigator Award (to RVT), and a Welcome Trust Clinical Training Fellowship (to VJS). We thank Mark Stevenson (University of Oxford, United Kingdom) for assistance in the analysis of human DNA-sequencing data and Donald Ward (University of Manchester, United Kingdom) and Arthur Conigrave (University of Sydney, Australia) for assistance in initial Affymetrix Microarray Analyses.

Address correspondence to: Kai Lau, 825 NE 10th Street, Suite 4E, Oklahoma City, Oklahoma 73104, USA. Phone: 405.271.8478; Email: kai-lau@ouhsc.edu. Or to: Leonidas Tsiokas, University of Oklahoma Health Sciences Center, 975 NE 10th St., BRC262, Oklahoma City, Oklahoma 73104, USA. Phone: 405.271.8001 ext. 46211; Email: 1tsiokas@ouhsc.edu. Or to: Mary Beth Humphrey, University of Oklahoma Health Sciences Center, 975 NE 10th St., BRC256, Oklahoma City, Oklahoma 73104, USA. Phone: 405.271.7712; Email: marybeth-humphrey@ouhsc.edu. 
CMG's present address is: Institute of Metabolism and Systems Research and Centre for Membrane Proteins and Receptors, University of Birmingham, Birmingham, United Kingdom.

1. Pollak MR, Seidman CE, Brown EM. Three inherited disorders of calcium sensing. Medicine (Baltimore). 1996;75(3):115-123.

2. Pollak MR, et al. Mutations in the human $\mathrm{Ca}(2+)$-sensing receptor gene cause familial hypocalciuric hypercalcemia and neonatal severe hyperparathyroidism. Cell. 1993;75(7):1297-1303.

3. Nesbit MA, et al. Mutations affecting G-protein subunit $\alpha 11$ in hypercalcemia and hypocalcemia. $N$ Engl J Med. 2013;368(26):2476-2486.

4. Nesbit MA, et al. Mutations in AP2S1 cause familial hypocalciuric hypercalcemia type 3. Nat Genet. 2013;45(1):93-97.

5. Lee JY, Shoback DM. Familial hypocalciuric hypercalcemia and related disorders. Best Pract Res Clin Endocrinol Metab. 2018;32(5):609-619.

6. Hannan FM, Kallay E, Chang W, Brandi ML, Thakker RV. The calcium-sensing receptor in physiology and in calcitropic and noncalcitropic diseases. Nat Rev Endocrinol. 2018;15(1):33-51.

7. Shoback DM, Thatcher J, Leombruno R, Brown EM. Relationship between parathyroid hormone secretion and cytosolic calcium concentration in dispersed bovine parathyroid cells. Proc Natl Acad Sci USA. 1984;81(10):3113-3117.

8. Hannan FM, Thakker RV. Calcium-sensing receptor (CaSR) mutations and disorders of calcium, electrolyte and water metabolism. Best Pract Res Clin Endocrinol Metab. 2013;27(3):359-371.

9. Conigrave AD. The calcium-sensing receptor and the parathyroid: past, present, future. Front Physiol. 2016;7:563.

10. Prakriya M, Lewis RS. Store-operated calcium channels. Physiol Rev. 2015;95(4):1383-1436.

11. Clapham DE. TRP channels as cellular sensors. Nature. 2003;426(6966):517-524.

12. Venkatachalam K, Montell C. TRP channels. Annu Rev Biochem. 2007;76:387-417.

13. Nesin V, Tsiokas L. TRPC1. Handb Exp Pharmacol. 2014;222:15-51.

14. Greenberg HZE, et al. Heteromeric TRPV4/TRPC1 channels mediate calcium-sensing receptor-induced nitric oxide production and vasorelaxation in rabbit mesenteric arteries. Vascul Pharmacol. 2017;96-98:53-62.

15. Rey O, Young SH, Jacamo R, Moyer MP, Rozengurt E. Extracellular calcium sensing receptor stimulation in human colonic epithelial cells induces intracellular calcium oscillations and proliferation inhibition. J Cell Physiol. 2010;225(1):73-83.

16. Rey O, Young SH, Papazyan R, Shapiro MS, Rozengurt E. Requirement of the TRPC1 cation channel in the generation of transient Ca2+ oscillations by the calcium-sensing receptor. J Biol Chem. 2006;281(50):38730-38737.

17. $\mathrm{Qu} \mathrm{YY}$, et al. TRPC1 stimulates calcium-sensing receptor-induced store-operated $\mathrm{Ca} 2+$ entry and nitric oxide production in endothelial cells. Mol Med Rep. 2017;16(4):4613-4619.

18. E1 Hiani Y, et al. Extracellular signal-regulated kinases 1 and 2 and TRPC1 channels are required for calcium-sensing receptor-stimulated MCF-7 breast cancer cell proliferation. Cell Physiol Biochem. 2009;23(4-6):335-346.

19. Dietrich A, et al. Pressure-induced and store-operated cation influx in vascular smooth muscle cells is independent of TRPC1. Pflugers Arch. 2007;455(3):465-477.

20. Jakobsen NF, Rolighed L, Moser E, Nissen PH, Mosekilde L, Rejnmark L. Increased trabecular volumetric bone mass density in Familial Hypocalciuric Hypercalcemia (FHH) type 1: a cross-sectional study. Calcif Tissue Int. 2014;95(2):141-152.

21. Christensen SE, et al. Skeletal consequences of familial hypocalciuric hypercalcaemia vs. primary hyperparathyroidism. Clin Endocrinol (Oxf). 2009;71(6):798-807.

22. Cheng Z, et al. Sex and age modify biochemical and skeletal manifestations of chronic hyperparathyroidism by altering target organ responses to Ca2+ and parathyroid hormone in mice. J Bone Miner Res. 2013;28(5):1087-1100.

23. Ong EC, et al. A TRPC1 protein-dependent pathway regulates osteoclast formation and function. J Biol Chem. 2013;288(31):22219-22232.

24. Rogers A, et al. Mutational analysis of the adaptor protein 2 sigma subunit (AP2S1) gene: search for autosomal dominant hypocalcemia type 3 (ADH3). J Clin Endocrinol Metab. 2014;99(7):E1300-E1305.

25. Chang W, Tu C, Chen TH, Bikle D, Shoback D. The extracellular calcium-sensing receptor (CaSR) is a critical modulator of skeletal development. Sci Signal. 2008;1(35):ra1.

26. Fabbri S, et al. PTH-C1: a rat continuous cell line expressing the parathyroid phenotype. Endocrine. 2014;47(1):90-99.

27. Rubaiy HN, et al. Picomolar, selective, and subtype-specific small-molecule inhibition of TRPC $1 / 4 / 5$ channels. J Biol Chem. 2017;292(20):8158-8173.

28. Kim MS, Zeng W, Yuan JP, Shin DM, Worley PF, Muallem S. Native store-operated Ca2+ influx requires the channel function of Orai1 and TRPC1. J Biol Chem. 2009;284(15):9733-9741.

29. Nesin V, et al. Activating mutations in STIM1 and ORAI1 cause overlapping syndromes of tubular myopathy and congenital miosis. Proc Natl Acad Sci USA. 2014;111(11):4197-4202.

30. Yoshida $\mathrm{H}$, et al. Membrane potential modulation of ionomycin-stimulated $\mathrm{Ca}(2+)$ entry via $\mathrm{Ca}(2+) / \mathrm{H}(+)$ exchange and $\mathrm{SOC}$ in rat submandibular acinar cells. J Physiol Sci. 2010;60(5):363-371.

31. Obukhov AG, et al. Direct activation of trpl cation channels by G alpha11 subunits. EMBO J. 1996;15(21):5833-5838.

32. Chang W, Shoback D. Extracellular Ca2+-sensing receptors--an overview. Cell Calcium. 2004;35(3):183-196.

33. Brown EM, Pollak M, Hebert SC. The extracellular calcium-sensing receptor: its role in health and disease. Annu Rev Med. 1998;49:15-29.

34. Christensen SE, et al. Plasma 25-hydroxyvitamin D, 1,25-dihydroxyvitamin D, and parathyroid hormone in familial hypocalciuric hypercalcemia and primary hyperparathyroidism. Eur J Endocrinol. 2008;159(6):719-727.

35. Christensen SE, Nissen PH, Vestergaard P, Mosekilde L. Familial hypocalciuric hypercalcaemia: a review. Curr Opin Endocrinol Diabetes Obes. 2011;18(6):359-370.

36. Vargas-Poussou R, et al. Familial hypocalciuric hypercalcemia types 1 and 3 and primary hyperparathyroidism: similarities and 
differences. J Clin Endocrinol Metab. 2016;101(5):2185-2195.

37. Davies M, et al. Familial hypocalciuric hypercalcaemia: observations on vitamin D metabolism and parathyroid function. Acto Endocrinol. 1983;104(2):210-215.

38. Law WM, Bollman S, Kumar R, Heath H. Vitamin D metabolism in familial benign hypercalcemia (hypocalciuric hypercalcemia) differs from that in primary hyperparathyroidism. J Clin Endocrinol Metab. 1984;58(4):744-747.

39. Szalat A, et al. Stepwise CaSR, AP2S1, and GNA11 sequencing in patients with suspected familial hypocalciuric hypercalcemia. Endocrine. 2017;55(3):741-747.

40. Toka HR, et al. Deficiency of the calcium-sensing receptor in the kidney causes parathyroid hormone-independent hypocalciuria. J Am Soc Nephrol. 2012;23(11):1879-1890.

41. Kristiansen JH, Rødbro P, Christiansen C, Johansen J, Jensen JT. Familial hypocalciuric hypercalcaemia. III: Bone mineral metabolism. Clin Endocrinol (Oxf). 1987;26(6):713-716.

42. Ho C, et al. A mouse model of human familial hypocalciuric hypercalcemia and neonatal severe hyperparathyroidism. Nat Genet. 1995;11(4):389-394.

43. Howles SA, et al. Cinacalcet corrects hypercalcemia in mice with an inactivating Ga11 mutation. JCI Insight. 2017;2(20):96540.

44. Offermanns S, Zhao LP, Gohla A, Sarosi I, Simon MI, Wilkie TM. Embryonic cardiomyocyte hypoplasia and craniofacial defects in G alpha q/G alpha 11-mutant mice. EMBO J. 1998;17(15):4304-4312.

45. Wettschureck N, Lee E, Libutti SK, Offermanns S, Robey PG, Spiegel AM. Parathyroid-specific double knockout of Gq and G11 alpha-subunits leads to a phenotype resembling germline knockout of the extracellular Ca2+ -sensing receptor. Mol Endocrinol. 2007;21(1):274-280.

46. Wes PD, Chevesich J, Jeromin A, Rosenberg C, Stetten G, Montell C. TRPC1, a human homolog of a Drosophila store-operated channel. Proc Natl Acad Sci USA. 1995;92(21):9652-9656.

47. Stormorken H. [Stormorken's syndrome]. Tidsskr Nor Laegeforen. 2002;122(30):2853-2856.

48. Myeong J, et al. Dual action of the G $\alpha_{\mathrm{q}}$-PLC $\beta-\mathrm{PI}(4,5) \mathrm{P}_{2}$ pathway on TRPC1/4 and TRPC1/5 heterotetramers. Sci Rep. 2018;8(1):12117.

49. Zheng W, et al. Direct binding between pre-S1 and TRP-like domains in TRPP channels mediates gating and functional regulation by PIP2. Cell Rep. 2018;22(6):1560-1573.

50. Reiniger N, et al. Deletion of the receptor for advanced glycation end products reduces glomerulosclerosis and preserves renal function in the diabetic OVE26 mouse. Diabetes. 2010;59(8):2043-2054.

51. Ma R, Rundle D, Jacks J, Koch M, Downs T, Tsiokas L. Inhibitor of myogenic family, a novel suppressor of store-operated currents through an interaction with TRPC1. J Biol Chem. 2003;278(52):52763-52772.

52. Hannan FM, Babinsky VN, Thakker RV. Disorders of the calcium-sensing receptor and partner proteins: insights into the molecular basis of calcium homeostasis. J Mol Endocrinol. 2016;57(3):R127-R142. 